\title{
ESCOLAS MULTISSERIADAS RURAIS NO ESTADO DO TOCANTINS E PEDAGOGIA HISTÓRICO-CRÍTICA: APROXIMAÇÕES
}

\author{
Klívia de Cássia Silva Nunes ${ }^{1}$ \\ Maria Cristina dos Santos Bezerra ${ }^{2}$
}

\begin{abstract}
Resumo
O presente trabalho aborda as práticas pedagógicas existentes nas escolas multisseriadas de 08 povoados rurais do município de Tocantinópolis/TO a partir da perspectiva dos docentes. Tomamos como referência de análise a Pedagogia Histórico-Crítica (PHC) tendo como fio condutor o seguinte questionamento: como os professores se posicionam diante das práticas pedagógicas que desenvolvem nas escolas multisseriadas rurais? Os dados aqui apresentados foram coletados no decorrer de um projeto de extensão integrado a pesquisa sobre o ensino em salas multisseriadas para o qual optou-se pela realização da pesquisa teórica e de campo. O resultado, ainda que provisório, proporcionou uma visão geral sobre a prática dos professores das escolas multisseriadas rurais no município estudado, que em suas falas demonstraram receber pouca orientação e subsídios sobre didática que facilitem trabalhar nestas escolas. Constatou-se também que há necessidade de adotar uma visão mais crítica na formação dos filhos dos trabalhadores do campo, de forma que compreendam a situação de dominação atual e, vemos na Pedagogia Histórico Crítica um referencial teórico-prático que possibilita desenvolver esse tipo de formação que vai além do trabalho escolar, preparando o indivíduo para sua inserção social pautada em conteúdos sólidos.
\end{abstract}

Palavras-chave: Pedagogia Histórico-Crítica. Prática pedagógica. Escola multisseriada rural.

\section{RURAL MULTIGRADE SCHOOLS AT TOCANTINS'STATE AND THE CRITICAL-HISTORIC PEDAGOGY: CONVERGENCES}

\begin{abstract}
This research approaches the educational practices by teachers' stance in multigrade schools in 08 rural towns from Tocantinopolis's county. The analyses were carry out by CriticalHistoric Pedagogy source and as a core question were inquired: how is the teachers' standpoints towards educational practices performed in rural multigrade schools? The data were collected during an extension program combined the theoretical and empirical research. The interim outcomes show a general view on the teachers' work into rural multigrade schools in the specific county, and also reveals in teachers' speech they had low instruction and support about a pedagogy to make easy the job on the schools. Was either verified there
\end{abstract}


is a need to get a critical view on the rural labor' son instruction in a way that understands the current dominance situation and, we do consider the Critical-Historic Pedagogy as empirical practical resource that enables to develop the sort of training beyond school practice, preparing the fellow members to take part in the society based on solid contents.

Keywords: Critical-Historic pedagogy. Educational practice. Rural Muligrade school.

\title{
ESCUELAS MULTISSERIADAS RURALES EN EL ESTADO DE TOCANTINS Y PEDAGÓGICA HISTÓRICO CRÍTICA: APROXIMACIONES
}

\begin{abstract}
Resumen
El presente trabajo aborda las prácticas pedagógicas existentes en las escuelas multiserarias de 08 poblados rurales del municipio de Tocantinópolis/TO desde la perspectiva de los docentes. Tomamos como referencia de análisis la Pedagógica a Histórico-Crítica (PHC) teniendo como hilo conductor el siguiente cuestionamiento: cómo los profesores se posicionan ante las prácticas pedagógicas que se desarrollan en las escuelas multiseriadas rurales? Los datos aquí presentados fueron recolectados en el transcurso de un proyecto de extensión integrado a la investigación sobre la enseñanza en salas multiseriadas para lo cual se optó por la realización de la investigación teórica y de campo. El resultado, aunque provisional, proporcionó una visión general sobre la práctica de los profesores de las escuelas multiseriadas rurales en el municipio estudiado, que en sus discursos demostraron recibir poca orientación y subsidios sobre didácticas que faciliten trabajar en estas escuelas. Se constató también que hay necesidad de adoptar una visión más crítica en la formación de los hijos de los trabajadores del campo, de forma que comprendan la situación de dominación actual y, vemos en la Pedagógica Histórico Crítica un referencial teórico-práctico que posibilita desarrollar ese tipo de formación que va más allá del trabajo escolar, preparando al individuo para su inserción social pautada en contenidos sólidos.
\end{abstract}

Palabras clave: Pedagógica Histórico-Crítica. Práctica pedagógica. Escuela Multiseriada rural.

\section{INTRODUÇÃO}

O presente texto aborda práticas pedagógicas de professores que atuam nas escolas multisseriadas no município de Tocantinópolis, localizadas na região do Bico do Papagaio, estado do Tocantins, a partir de suas perspectivas, tendo como referência de análise a Pedagogia Histórico-Crítica (PHC), que permite uma melhor compreensão sobre os desafios educacionais que os professores enfrentam, especialmente, com turmas multisseriadas. 


\section{Revista HIISTEADIBR On-line}

Artigo

doi: $10.20396 /$ rho.v18i1.8645922

De acordo com dados do Instituto Nacional de Estudos e Pesquisas Educacionais Anísio Teixeira (BRASIL, 2017), o Brasil tem 186,1 mil escolas de educação básica das quais $33,9 \%$ se encontram na zona rural. Uma característica marcante nessas escolas rurais é a quantidade de alunos que são atendidos: $41,2 \%$ delas têm até 50 matrículas nos anos iniciais e apenas 3,7\% têm mais de 500 . Quanto aos professores, "19,9 mil escolas que oferecem anos iniciais têm apenas um docente atuando nessa etapa. Quase a totalidade encontra-se na zona rural $(95,1 \%)$ )" (BRASIL, 2017, p. 7), o que demonstra que a forma de organização multissérie unidocente persiste em comunidades rurais de pouca densidade populacional e de difícil acesso.

Além disso, há de se considerar que num país com tanta diversidade territorial, a escola multisseriada caracteriza uma realidade comum, especialmente nas regiões Norte e Nordeste brasileiro, sendo vista de forma negativa segundo alguns autores, mas, positivamente por outros que estão envolvidos com a questão da educação do e no campo.

A perspectiva negativa se ancora no fato de ser uma escola em que trabalha um único professor com várias séries e níveis de ensino no mesmo espaço, sendo tratada como um mal necessário, causando tensões entre os educadores, pesquisadores e movimentos sociais, por ligar esta escola ao atraso e a má qualidade do ensino. Eliane Dayse Pontes Furtado (2004) afirma que as escolas multisseriadas estão geralmente associadas ao baixo desempenho escolar e a falta de preparação específica dos professores para atuarem neste tipo de escola.

Por outro lado, Arroyo (2010) reforça a importância da desconstrução deste imaginário negativo sobre as escolas multisseriadas e a necessidade de mostrar que a difusão desse ideário tem uma intencionalidade por parte do poder público que é forjar políticas que as tornem invisíveis e/ou inexistentes. Acrescenta, que enquanto persistir estes imaginários hierarquizantes, inferiorizantes, segregadores, as pesquisas e análises nascerão viciadas e preconceituosas. Neste sentido, é preciso ter um olhar em outra direção, “[...] que as escolas multisseriadas estão sendo levadas a sério, sendo reinventadas, e não mais ignoradas nem desprezadas como escolas do passado.” (ARROYO, 2010, p. 10).

Mas o que vem a ser uma escola multisseriada? De acordo com Maria Angélica Cardoso (2013) para se ter clareza do que é multisseriação, implica antes de tudo conceituar o que vem a ser seriação. "A seriação significa divisão de acordo com uma classificação. Nas escolas indica a organização dos alunos em classes graduadas e em agrupamentos, segundo a idade e o nível de desenvolvimento." (CARDOSO, 2013, p. 33). Quanto a multisseriada, a autora diz que o termo vem de multi que indica abundância, numerosidade, quantidade. Assim, a multisseriação indica muitas séries, no caso brasileiro, muitos anos. (CARDOSO, 2013). Deste modo, "[...] as escolas multisseriadas são organizadas, mantendo em uma mesma sala de aula, várias séries (anos) sob a regência de um só professor, sendo, por isso, também denominada de escolas unidocentes." (CARDOSO, 2013, p. 33). 
Nesta mesma linha de entendimento, o documento intitulado Panorama da Educação do Campo (BRASIL, 2007, p. 25) tem a seguinte definição:

\begin{abstract}
As classes multisseriadas têm alunos de diferentes séries e níveis em uma mesma sala de aula, independente do número de professores responsável pela classe. A unidocência ocorre quando um único professor é responsável pela condução do desenvolvimento de uma classe multisseriada. Embora possa acontecer de uma escola ou classe ser multisseriada e ter mais de um professor, as escolas multisseriadas do campo contam, na quase totalidade dos casos, com apenas um professor, o que torna unidocência e multisseriação termos equivalentes.
\end{abstract}

Embora o modelo sobreviva ao tempo e esteja previsto no artigo $23^{\circ}$ da Lei de Diretrizes e Bases da Educação Nacional (LDBEN 9394/96), essa forma de organização de ensino ainda é pouco conhecida e praticamente ausente nos cursos de formação de professores, o que torna o desafio para quem ingressa em uma sala dessas, ainda maior. Esse fato por si só nos incentiva a falar sobre processos educativos que se concretizam no interior da escola multisseriada, visto que é um desafio para os professores trabalharem com todos os anos escolares e/ou etapas ${ }^{3}$ de ensino, considerando o ritmo de aprendizagem de cada aluno, diferença de idade, a própria formação do professor que enfatiza uma prática seriada $\mathrm{e}$, ainda, o não entendimento de como trabalhar com as escolas rurais a partir da realidade dos trabalhadores do campo e o vínculo da educação com a luta pela terra.

Mesmo com esses fatores que envolvem as escolas multisseriadas, as práticas pedagógicas que nelas se materializam têm os mesmos objetivos que as demais, ou seja, a transmissão do conhecimento, fundamental para a formação humana e, portanto, requer um projeto pedagógico sistematizado e intencional, que ajude os alunos a compreender criticamente a sociedade em que estão inseridos para, a partir desta compreensão, participar ativamente no processo de transformação social. Como afirma Medeiros (2010, p. 59), essa estrutura escolar é complexa, e requer que os profissionais que nelas lecionam, “[...] tenham condições didáticas, pedagógicas e técnicas (dentre outras) diferenciadas face às exigências da situação e contexto."

Considerando essas questões, apresentamos resultados de uma pesquisa realizada com docentes de escolas multisseriadas no município de Tocantinópolis-TO que buscou captar, a partir de suas falas, a percepção que eles têm sobre suas práticas pedagógicas nestas escolas à luz da pedagogia histórico-crítica.

Aqui reside a importância de analisar esta realidade a partir da PHC, por ser uma teoria com uma sólida base filosófico-pedagógica que possibilita a compreensão, em sua totalidade, das relações sócio históricas na qual os sujeitos estão inseridos, seja no campo ou seja na cidade, tendo como premissa básica a tomada de posicionamento diante dos problemas postos pela prática social. Acreditamos que a PHC contribui no entendimento e 
análise do trabalho realizado nas escolas multisseriadas, tendo em vista a compreensão da sociedade e, da educação, visando a superação da fragmentação da realidade. (ORSO, 2016).

\section{AS PRÁTICAS PEDAGÓgICAS DOS PROFESSORES DAS ESCOLAS MULTISSERIADAS}

Sabemos que o trabalho do professor de educação básica está ficando cada vez mais complexo diante dos desafios impostos pela proposta educacional capitalista que, além de esvaziar seu trabalho de sentido e de conteúdo, lhes atribui tarefas que ultrapassam o limite do ensino.

Para os professores de escolas multisseriadas, soma-se a isso o agrupamento de alunos de diferentes faixas etárias e níveis de conhecimento em uma mesma sala de aula, ao mesmo tempo, sob a condução de um único professor, via de regra, o único profissional presente na comunidade escolar. Embora seja difícil, não é impossível, desde que haja articulação do conteúdo de ensino com os anos escolares por meio de um trabalho pedagógico sistematicamente bem orientado.

$\mathrm{Na}$ pesquisa selecionamos os 08 povoados do município de Tocantinópolis/TO: Folha Grossa, Pedro Bento, Chapadinha, Mumbuca, Ribeirãozinho, Olho d'água, Rodagem e Passarinho. Contou com a participação de 19 professores dos 22 que trabalhavam nas escolas situadas nos referidos povoados. Realizamos entrevistas semiestruturadas e grupo focal com os professores, duas técnicas importantes para coletada dos dados. As entrevistas forneceram as primeiras informações sobre o objeto de estudo e foram realizadas no período de 2013 a 2014. Já o trabalho com o grupo focal foi realizado em 2014 com a finalidade complementar, esclarecer e aprofundar as perguntas que foram realizadas na entrevista, o que exigiu dois encontros em virtude do número de participantes. No primeiro encontro participaram 10 professores e no segundo 09, discutindo a mesma questão nos dois grupos.

Para uma maior compreensão, os dados coletados foram tabulados de acordo com três categorias empíricas ${ }^{4}$ : trabalho docente, atividade curricular e práxis pedagógica, que permitiram evidenciar a visão dos professores em relação as suas práticas pedagógicas.

Como forma de contextualizar de onde se fala e de quem se fala, optou-se por traçar o perfil das escolas, de forma a retratar este universo. Dos povoados pesquisados, foi encontrada a seguinte situação: as escolas localizadas nos povoados de Chapadinha, Mumbuca, Ribeirãozinho e Rodagem tem número reduzido de alunos, menos de 20, o que demonstra certo esvaziamento na escola; sendo que a escola do povoado de Rodagem, fechou no final de 2013, naquele ano a escola contava com 17 alunos matriculados atendendo do $1^{\circ}$ ano até o $3^{\circ}$ ano do ensino fundamental, não houve a preocupação do poder público em explicar as razões que levaram ao fechamento da escola. Em 2014 as escolas localizadas 
respectivamente no povoado de Ribeirãozinho e Mumbuca não mais oferecem $4^{\circ}$ e $5^{\circ}$ ano do ensino fundamental e a escola localizada no povoado de Chapadinha só oferece educação infantil.

Tal situação encontrada causa estranheza e preocupação, pois aos poucos a escola está deixando de oferecer os anos escolares, minguando número de alunos e, no futuro próximo, pode levá-las ao fechamento, ou melhor, dizendo, na prática estão realizando um "fechamento por dentro da escola". Mas o que entendemos por "fechamento por dentro da escola"? Entendemos que é uma prática silenciosa de fechamento de escola da zona rural, através da não oferta dos anos mais avançados, $4^{\circ}$ e $5^{\circ}$ ano, com isso, os pais que têm filhos nestes anos e nos anteriores acabam por optar em matricular os seus filhos em uma escola que oferte o ensino fundamental completo, no caso, a escola da zona urbana. Além disso, os outros anos $1^{\circ}$ ao $3^{\circ}$ e o pré-escolar, aos poucos vão deixando de serem ofertados. Importa considerar que esta prática infringe a Lei ${ }^{\circ}$ 12.960, de 27 de março de 2014, no artigo 28, parágrafo único, que dispõe:

Art. 28. Parágrafo único. O fechamento de escolas do campo, indígenas e quilombolas será precedido de manifestação do órgão normativo do respectivo sistema de ensino, que considerará a justificativa apresentada pela Secretaria de Educação, a análise do diagnóstico do impacto da ação e a manifestação da comunidade escolar. (BRASIL, 2014).

O que significa dizer sobre a questão posta, é que a comunidade não toma conhecimento sobre os verdadeiros motivos que levaram ao fechamento, somente percebe que a escola foi fechada quando o fato é consumado, não havendo tempo para reverter tal situação, tal como foi constatado nas escolas pesquisadas. Existem algumas justificativas que o poder público local recorre para continuar com esta prática e com o não cumprimento a lei, são: os alunos se mudaram para outro povoado e/ou outra cidade; não gostam da escola e preferem a escola da cidade e, por aí vai. E, ainda, justificam: está tudo de acordo com lei.

Quanto ao perfil dos professores temos o seguinte: a) Moradia (campo/cidade): 06 professores moram na zona rural, 12 na zona urbana e 01 não respondeu; b) Formação inicial: 11 são formados em pedagogia; 03 apenas com ensino médio; 01 formado em normal superior, 01 formado em geografia, 01 formado em matemática, 01 cursando pedagogia; c) Formação continuada em educação do campo: todos afirmaram que já participaram de formação promovida pela Secretaria Municipal de Educação do município.

Posto isso, passamos a relatar o que foi coletado no trabalho de campo. Ao se perguntar para os professores o maior desafio que enfrentavam na condução de seu trabalho na escola multisseriada, responderam: 
Quadro 1 - Quanto ao trabalho docente

\begin{tabular}{|l|l|}
\hline Categoria & Resultado \\
\hline \multirow{4}{*}{ Trabalho docente } & Consideram um problema a relação escola e família \\
\cline { 2 - 2 } & Pouca formação continuada sobre educação do campo \\
\cline { 2 - 2 } & Dificuldade de trabalhar com a sala multisseriada \\
\cline { 2 - 2 } & Planejamento diversificado para atender as séries \\
\cline { 2 - 2 } & Alunos com ritmo de aprendizagem diferente \\
\cline { 2 - 2 } & Falta de material didático \\
\hline
\end{tabular}

Fonte: elaborado pela pesquisadora/2015

\section{RELAÇÃO FAMÍLIA-ESCOLA}

Ao analisarmos a dificuldade que os professores enfrentam em relação a integração escola e família, compreendemos que as duas instituições são necessárias para o desenvolvimento dos alunos, sendo a função primordial da escola o processo de ensino e aprendizagem, e da família, educar, proteger e garantir sua sobrevivência, mas também não exclui a responsabilidade da família em cultivar atitudes positivas em relação ao estudo de seus filhos. Mas vale dizer que não se pode "[...] cair no equívoco de delegar aos pais e à comunidade aquilo que compete ao Estado, por meio da escola, realizar." (PARO, 2001, p. 67). Por outro lado, cabe à família participar nas tomadas de decisão na escola, em todas as suas dimensões (administrativa, financeira e pedagógica), de forma que contribua com a discussão que giram em torno do planejamento das ações e objetivos educacionais, investindo na melhoria da qualidade de educação ofertada a seus filhos. (PARO, 2001).

Em suma, não se pode perder de vista, quando se discute a relação escola e família, que a função da escola é estritamente pedagógica, ligada à transmissão do conhecimento científico, residindo aí sua importância que não pode ser secundarizada. (SAVIANI, 2008). Não se pode fazer a inversão, colocando a família como a instituição mais importante no ato educativo, pois essa competência cabe ao espaço escolar. Compreende-se, portanto, que trazer a família para escola não significa transferir sua atribuição a família e nem tão pouco ser uma agência de assistência social, mas a instituição que dissemina o saber construído historicamente pela humanidade.

\section{FORMAÇÃO ESPECÍFICA PARA EDUCAÇÃO NO CAMPO}

Em se tratando da formação continuada, mesmo os professores afirmando que participaram de capacitações sobre educação do campo oferecida pela Secretaria Municipal de Educação, ainda assim, consideram insuficiente, visto que os mesmos apontam a falta de formação específica como um dos principais problemas que enfrentam. Indagamos: há necessidade de uma formação específica para a educação no campo? Como esta formação 
está sendo realizada? Ela atende às necessidades destes professores? Possibilita aos professores passarem da síncrese à síntese?

Na verdade, estas questões demonstram que as políticas para a educação do campo estão postas e garantidas no papel, que se materializam nas Diretrizes, Resoluções e Leis destinadas a educação do campo, inclusive reconhece que a educação é um direito, (da educação infantil ao ensino superior), assegurando dispositivos legais que afirmam a diversidade da polução do campo,

[...] compreendidas enquanto agricultores familiares, extrativistas, pescadores artesanais, ribeirinhos, assentados e acampados da reforma agrária, trabalhadores rurais assalariados, [...] e outros que produzam suas condições materiais de existência a partir do trabalho no meio rural. (HAGE, 2014, p. 1169),

O que a prática revela é que a Secretaria Municipal de Educação do município de Tocantinópolis negligencia, na formação, a discussão sobre a especificidade, ficando em segundo plano diante de outras prioridades, como é o caso da formação do Pacto Nacional pela Alfabetização na Idade Certa $^{5}$ (PNAIC), que embora encampe a formação específica para o campo, nas escolas estudadas não atingiu as expectativas dos professores.

Não queremos afirmar com isso que há necessidade de uma educação específica, de uma formação específica para cada região, por exemplo campo e cidade, e nem que deva haver uma educação específica para cada uma dessas frações da classe trabalhadora que vive e tira seu sustento do campo pois,

[...] se entendermos que o processo educacional deve ocorrer no local em que as pessoas residem, devemos falar de uma educação no campo e aí, não haveria a necessidade de se pensar em uma educação específica para o campo, dado que os conhecimentos produzidos pela humanidade devem ser disponibilizados para toda a sociedade. (BEZERRA NETO, 2010, p. 152).

No caso do campo, nomeadamente, se nos rendermos ao discurso da especificidade, vamos cair no canto da sereia da diversidade, que divide a classe trabalhadores em diferentes "categorias" sociais que são separadas por etnia, gênero, geração e, local de moradia. Os avanços do capital na desmobilização da classe trabalhadora se materializam nesse ideário de que para cada comunidade específica, deva existir uma escola específica e conteúdo específicos, pois os interesses socioculturais de cada grupo são diferentes, portanto, específicos! Nesse processo, embora se tenha pouca consciência disso, o capital fragmenta a classe trabalhadora que passa a defender interesses particulares de grupos culturais, perdendo a dimensão da totalidade, "[...] que é o pertencer a uma única classe social, a classe dos desprovidos dos meios de produção e por isso, vendedores de força de trabalho, explorados pelo capital.” (BEZERRA NETO, 2010, p. 152). 
Não queremos dizer com isso, entretanto, que a escola rural não tenha nada que a diferencie das congêneres urbanas. A especificidade está na multisseriação, na unidocência, nas difíceis condições de acessibilidade, tanto por parte de alunos quanto de professores, na dificuldade de acesso a materiais didáticos, tecnológicos, esportivos, apoio humano e as mesmas informações que os demais alunos têm (ou deveriam ter).

\section{TRABALHO NA SALA MULTISSERIADA}

A pesquisa também revelou que os professores têm dificuldades em trabalhar com as salas multisseriadas por não compreenderem o "como fazer", conforme descrito no quadro 01 e nas falas:

\footnotetext{
Professor A: o grande desafio é trabalhar com várias séries juntas e desenvolver as habilidades necessárias dentro do tempo esperado [...].

Professora B: já trabalho em escola com turmas multisseriadas há três anos e nem por isso minhas dificuldades foram sanadas. Não me identifico nem um pouco com esta metodologia me sinto impotente por não fazer um trabalho de qualidade [...].

Professora C: o maior desafio é fazer um planejamento para diferentes níveis de aprendizagem $[\ldots]$.

Professor D: [...] a escola urbana é melhor por possuir mais recursos didáticos para trabalhar com os conteúdos na sala de aula [...]. É muito complicado você entrar em sala e se deparar com várias crianças, em vários níveis e série diferente. Já é difícil trabalhar com níveis diferentes em uma série e mais de uma, duas, três. Detesto salas multisseriadas. (Informação Verbal).
}

Estas falas refletem o que os professores estão enfrentando no que consiste no despreparo para a atuação neste tipo de sala de aula, o que gera o descontentamento com seu trabalho e com a escola multisseriada. Essas escolas sempre foram tratadas como as urbanas, utilizando o mesmo tipo de livro didático, os professores participando de reuniões pedagógicas conjuntas, com o conteúdo da discussão sempre voltado para as turmas urbanas, as orientações didáticas para as salas seriadas, planejamento, enfim, uma discussão sobre a didática para as salas homogêneas. Há ainda hoje, falta de metodologia que direcione a prática pedagógica para as turmas multisseriadas, que causa insegurança e angústia nos professores, sem contar com o esgotamento, por ter que planejar, ensinar, avaliar e, por vezes, assumir outras funções não afeitas a seu cargo.

\section{PLANEJAMENTO}

Pode-se ainda acrescentar o desconhecimento em realizar o planejamento de ensino, que diga de passagem, é bem diferente do ato de planejar para as escolas seriadas, pois o trabalho com a sala multisseriada, por ter um número reduzido de alunos por turma, faz com que este professor tenha que trabalhar com a diversidade de alunos que estão em anos diversos e etapas de ensino diferentes, ou seja, turma heterogênea. Isto exige conhecimento em termos de estratégia de ensino específica para esta escola, com isso, os professores se 
sentem frágeis, pois na sua formação inicial não lhes foi ensinado como trabalhar estratégias metodológicas para turmas que não sejam no formato de seriação, e, a formação continuada, também não os ajuda muito, consequentemente, a dificuldade vai se reproduzindo repetidamente.

Essas questões nos levam a questionar a viabilidade desta escola para professores e alunos na transmissão do saber sistematizado, de forma que os alunos ampliem seus conhecimentos e visão de mundo.

Para responder tal questionamento, antes de tudo, deve-se compreender que o trabalho com as classes multisseriadas não pode ser via seriação ${ }^{6}$ (dividida em anos escolares) como via de regra fazem os professores na hora do planejamento anual e das aulas diárias. Primeiramente não haverá avanço significativo no atendimento pedagógico sem a “[...] superação de práticas pedagógicas assistemáticas e de uma concepção de planejamento pedagógico que, equivocadamente, o toma como sinônimo de organização da rotina institucional." (MARTINS; MARSIGLIA, 2015). Deve-se ter objetivos claros a atingir, ou seja, saber onde se quer chegar e o que fazer para chegar; o planejamento pedagógico não pode ser tomado como procedimento em si mesmo, esvaziado de conhecimento sobre a especificidade do desenvolvimento humano e do papel que a escola desempenha nele. De acordo com as autoras,

Cada objetivo traçado em um planejamento deve considerar o sujeito a quem se destina aquele conteúdo, o desenvolvimento conquistado por ele até então e as peculiaridades de sua faixa etária, sobretudo por sabermos que o desenvolvimento infantil não é garantido por fatores naturais, a exemplo da idade cronológica, mas por condições sociais de vida e de educação. (MARTINS; MARSIGLIA, 2015, p. 20).

Tomamos que em classes multisseriadas o planejamento ideal não seria um para cada ano de escolarização, mas um único planejamento para a turma toda, de acordo com as peculiaridades da faixa etária. Contando que as crianças de diferentes idades estão na mesma sala, ouvindo as mesmas coisas, os mesmos assuntos, os mesmos conteúdos que são apresentados a cada um dos anos, não é de se estranhar que eles acabem incorporando aquilo que ele é capaz de compreender de acordo com seu meio e idade.

O que vai diferenciar são as intervenções que a professora fará para cada ano e nível de desenvolvimento do aluno, para que possa ocorrer a aprendizagem, isto por que "o trabalho pedagógico em todas as áreas do conhecimento "[...] orienta-se tanto pelos domínios já conquistados quanto pelas demandas de aprendizagens que corroborem o desenvolvimento da linguagem escrita e de conceitos matemáticos." (MARTINS; MARSIGLIA, 2015, p. 20).

Os conteúdos, portanto, devem visar a elevação ao mais alto nível do desenvolvimento do sujeito e a escola é o espaço institucional para socialização do saber 
humano traduzido em saber escolar a ser transmitido com as formas mais adequadas a sua apropriação. (SAVIANI, 2008). Para que essa transmissão de conhecimento se dê de forma consistente, "[...] é fundamental conhecer os princípios científicos explicativos do processo de desenvolvimento cultural da criança bem como dominar os conhecimentos didáticopedagógicos necessários à organização de uma prática educativa consistente e humanizadora." (MARTINS; MARSIGLIA, 2015, p. 20).

Para isso, se faz necessário uma organização diversificada dos alunos em sala de aula: em grupos por idade, grupos heterogêneos, grupo com a sala toda, em duplas ou individual, justamente o que é mais rico neste tipo de organização, valorizando a troca de saberes entre os pares. Os registros gráficos também podem ocorrer de formas diversas, de acordo com aquilo que a criança domina: relatos orais, resolução de problemas, desenhos, produção de textos, elaboração de listas... Daí a importância de se conhecer o nível de desenvolvimento dos alunos para que se possam organizar os grupos de estudo na sala de aula de modo que todos possam aprender, sob a orientação do professor.

Assim, para o planejamento do trabalho educativo, o professor deve identificar os elementos culturais que precisam ser assimilados pelos indivíduos sem deixar de se preocupar com as formas mais adequadas de transmiti-los, para que os objetivos propostos pelo professor sejam efetivados no aluno. Quanto a identificação de elementos, esse envolve um esforço de distinguir o que é essencial do acidental, o que é principal do secundário, o que é fundamental e o que é acessório. Para daí sim, possibilitar o processo de conhecimento na “[...] passagem da síncrese à síntese pela mediação da análise." (SAVIANI, 2008, p. 142).

Um bom planejamento e condução do processo educativo requer uma ação pedagógica que se integre à realidade concreta, em busca da transformação da realidade social. Demerval Saviani (2008) mostra que a natureza e a especificidade da escola está na democratização do acesso à cultura humana, na produção de novos conhecimentos e na construção do pensamento social, inserido em situações concretas da realidade. Coloca a educação a serviço da transformação da sociedade desigual.

Portanto, "[...] assumir essa orientação pedagógica na atividade educativa significa ter presente o modo como está estruturada a sociedade atual no interior da qual os educandos nasceram." (SAVIANI, 2016, p. 23). Assim, para Saviani (2016) há necessidade de se "[...] compreender as determinações que se ocultam sob as aparências dos fenômenos" (SAVIANI, 2016, p. 23), o que significa entender de forma profunda como nasceu a sociedade, como se encontra estruturada.

O conhecimento sistematizado é imprescindível para a compreensão destas relações sociais, da historicidade do mundo atual, que possibilitará, não só pela educação, mas por todas as outras vias, a transformação social. 
Pensando a educação no campo, cabe ao professor compreender a "[...] essencialidade da terra para a vida humana" (SAVIANI, 2016, p. 25), a relação campo e cidade, compreender a histórica concentração da terra no Brasil, a questão agrária, a expulsão do trabalhador rural para outra cidade e região do Brasil, a produção dos insumos agroindustriais, o uso do agrotóxico, as questões ambientais, entre outros. (SAVIANI, 2016). Conforme foi exposto,

[...] este é o quadro em que se desenvolve a prática social do morador do campo. Na perspectiva da pedagogia histórico-crítica, o professor precisa ter clareza desse quadro já no ponto de partida, pois essa é uma condição para que ele possa concorrer, pelo trabalho educativo, para que os alunos ascendam a essa compreensão no ponto de chegada. (SAVIANI, 2016, p. 35-36).

Deste modo o professor deve, ao planejar suas aulas e colocá-las em prática, pensar o ponto de partida e o ponto de chegada mediados pela prática pedagógica. No entanto, se o professor não conhece a realidade ou nega esta realidade, ele não consegue realizar as mediações necessárias e adequadas para alcançar os objetivos propostos. Seu trabalho se torna uma prática esvaziada de sentido e/ou de conteúdo se não tiver um método que preconize a identificação dos principais problemas postos pela prática social, que procure detectar questões que precisam ser resolvidas no âmbito da prática social. (SAVIANI, 2007). Neste sentido, é imprescindível o planejamento adequado das aulas, pois o ensino é uma ação intencional que requer a articulação dialética entre os conceitos presentes no cotidiano dos alunos e a formação dos conceitos científicos.

Diante do exposto, ressalta-se que "[...] o conhecimento por si só não liberta o ser humano: o que liberta é a prática social" (GAMA; DUARTE, 2017, p. 527), da mesma forma que não tem como dizer que "[...] a socialização do saber sistematizado pela educação escolar promoveria, por si só, a libertação das pessoas" (GAMA; DUARTE, 2017, p. 527), isso seria puro idealismo.

As próximas falas mostram que nem tudo está perdido, há ainda possibilidade de se repensar um novo caminho.

Professor E: Trabalhar com séries multisseriadas é sempre um desafio. Mesmo assim, consigo me identificar [...]

Professor F: é trazer métodos de trabalho que possam contemplar estes alunos $[\ldots]$.

Professor G: independente se é seriada ou multisseriada, vai ser sempre encontrado desafios para a prática pedagógica [...]. (Informações Verbal).

Como demonstrado acima, existe a consciência de que é um desafio o que estão se propondo a realizar e, sabem que precisam alinhar suas práticas de forma a atingir o objetivo proposto, que é a aprendizagem dos alunos. 
Além disso, procuramos saber sobre como estava sendo desenvolvida a atividade curricular na escola no campo, o resultado foi sintetizado no quadro 2 .

Quadro 2- Quanto a atividade curricular

\begin{tabular}{|l|l|}
\hline Categoria & Resultado \\
\hline \multirow{4}{*}{$\begin{array}{l}\text { Atividade } \\
\text { Curricular }\end{array}$} & $\begin{array}{l}\text { Os professores consideram que devido à proximidade com a cidade os alunos e } \\
\text { a comunidade não se identificam com o campo, pois muitos pais trabalham na } \\
\text { cidade e outros vivem basicamente de benefícios sociais como o bolsa família. }\end{array}$ \\
\cline { 2 - 2 } & $\begin{array}{l}\text { Trabalham com os projetos da Secretaria da Saúde, tais como: Dia internacional } \\
\text { da mulher, dia nacional da nutrição, combate à dengue, dia nacional da } \\
\text { prevenção e combate à hipertensão, outros. }\end{array}$ \\
\hline
\end{tabular}

Fonte: elaborado pela pesquisadora/2015

Conforme relato dos professores sobre a concepção que a escola tem de si mesmo enquanto escola do campo, pode-se perceber que eles não consideram uma escola do campo, justificam as suas falas pela própria proximidade com a cidade. O que nos leva de volta a primeira indagação feita anteriormente, se de fato há necessidade de uma educação específica. Nossa conclusão é de que não há esta necessidade, mas há necessidade de se partir da prática social de onde o sujeito está inserido.

O estudo também aponta para um contexto de apropriação dos espaços escolares por parte de outros órgãos como os da saúde e as influências que o currículo da escola no campo sofre por parte dessas influências, uma vez que as mesmas utilizam-se da escola para desenvolver os seus projetos o que fragiliza ainda mais o processo educacional, por este motivo, os pais, e com todo razão, vislumbram outro tipo de educação para seus filhos, esta educação escolar não está no campo e sim na cidade. Desta forma alargam os problemas da escola, pois ao invés de atribuir-lhe a função que lhe cabe, assume papéis de diferentes modalidades de política social, colocando sob sua responsabilidade problemas de diferentes ordens que não são especificamente educacionais. (SAVIANI, 2007).

Quando esses projetos são impostos por outras secretarias, como saúde e meio ambiente, torna-se ainda mais necessário, por parte dos envolvidos com a educação, o reconhecimento da escola como lócus privilegiado de socialização da cultura em suas formas mais desenvolvidas. Recuperar os objetivos da instituição escolar, definir prioridades, decidir sobre o que é válido e o que não é, separar o que é essencial do que é secundário, é a única forma das ações da escola não serem secundarizadas no cumprimento de ações alheias ao seu projeto pedagógico e do planejamento escolar.

Assim, cabe aqui uma breve reflexão sobre o currículo na perspectiva da PHC, que reforça a importância de se tratar na escola o conjunto sistematizado do conhecimento produzido historicamente pela humanidade, considerando o enfoque científico e não o senso comum. Neste sentido, há necessidade de se preparar a condições de transmissão e apropriação desse conhecimento, o que requer a seleção de conteúdo, bem como, a forma de 
apresentação aos alunos (GAMA; DUARTE, 2017), mas foi justamente isso que não aconteceu e não se levou em conta quando as secretarias de saúde e meio ambiente realizaram suas ações na escola, não pensaram nas mediações que o processo pedagógico exige. A partir deste ponto, houve a necessidade de se perguntar aos professores sobres a práxis pedagógicas, as respostas foram sistematizadas no quadro 3.

Quadro 3- Quanto a práxis pedagógica

\begin{tabular}{|l|l|}
\hline Categoria & Resultado \\
\hline \multirow{4}{*}{ Práxis Pedagógica } & Falta de acompanhamento por parte da coordenação pedagógica \\
\cline { 2 - 3 } & $\begin{array}{l}\text { Planejam suas aulas com base na proposta curricular do campo elaborada } \\
\text { pela SEDUC/TO, juntamente com o livro didático (com proposta para } \\
\text { escola seriada e não multisseriada) e para o } 1^{\circ} \text { até o } 3^{\circ} \text { ano com a proposta } \\
\text { curricular do PNAIC. }\end{array}$ \\
\cline { 2 - 2 } & $\begin{array}{l}\text { A formação do PNAIC acontece com todos os professores juntos (zona } \\
\text { rural e urbana), sendo que pouco é tratado sobre a questão da escola do } \\
\text { campo. }\end{array}$ \\
\cline { 2 - 2 } & $\begin{array}{l}\text { Linha pedagógica que seguem: misturam Piaget, Vygotsky e Paulo } \\
\text { Freire. }\end{array}$ \\
\hline
\end{tabular}

Fonte: elaborado pela pesquisadora/2015.

Este quadro reforça o que já foi exposto anteriormente: falta de acompanhamento, planejamento desvinculado da realidade social dos alunos, currículo hierarquizado e falta de conhecimento teórico. O que chama a atenção nos pontos levantados, é que fica evidente que os professores estão completamente perdidos, precisando de auxilio e acompanhamento pedagógico para um bom desenvolvimento de sua prática. Há também a falta de conhecimentos teóricos sobre as teorias pedagógicas, o que nos leva a inferir que lhes falta um referencial teórico mais consistente que expresse um desejo de mudança dessa escola que se apresenta, mas esta mudança passa pela inter-relação entre teoria e prática.

Diante do exposto, se faz necessário dizer que para haver esta mudança nesta escola multisseriada, passa também pela mudança de concepção de mundo deste professor, aí reside a importância do conhecimento por parte dele sobre as teorias pedagógicas que embasam o seu fazer na sala de aula. Uma boa "[...] teoria fundada na prática que tende, por sua vez, a resolver - justamente por seu caráter rigoroso, científico, objetivo - as condições que se apresentam real e efetivamente." (VÁZQUEZ, 2011, p. 257). Aqui residem as observações de Saviani (2013) e Vázquez (2011) quando dizem que se deve trabalhar como ponto de partida e de chegada a prática social como forma de orientar a práxis pedagógica.

Para finalizar, dizemos que a educação, no caso, a escolar, por si só não realiza a transformação social desejada, pelo simples fato dela não ter poder para isso, mas é tomada aqui como uma tática política para o desenvolvimento da consciência de classe em vista da superação do que está posto atualmente. 


\section{CONSIDERAÇÕES FINAIS}

Ao final destas linhas, ressaltamos a relação dialética entre a educação e a sociedade, daí a importância de se pensar numa prática pedagógica que privilegie como ponto de partida e de chegada a prática social e tenha a práxis pedagógica como fundamento. Deste modo, pode-se inferir que por meio das relações sociais e materiais o homem constrói um saber sistematizado, efetivo e profundo. Neste sentido, pode-se dizer que esta relação da educação com a sociedade tanto é determinada como é determinante, consequentemente, ela pode também interferir sobre a sociedade, contribuindo para a transformação, porém, a educação sozinha não fará tal transformação, mas contribuirá para emancipação do homem, que se faz na prática social.

Tal pressuposto requer que se compreenda a educação como está posta atualmente, indo na sua raiz histórica, na compreensão do homem, no processo de produção da sua própria existência através do trabalho. Trabalhando o homem vai construindo um mundo histórico, um mundo da cultura, um mundo humano, aqui se encontram as origens do processo da educação. (SAVIANI, 2008). A escola não é o único lugar em que se aprende, mas é a instituição que por sua função específica que é educativa, pedagógica e ligada ao conhecimento científico, é a privilegiada na transmissão desses conhecimentos.

Mas está em curso o processo que visa secundarizar a escola, convertendo-a numa agência assistencialista, tratando-a como desnecessária, daí o esvaziamento das próprias propostas pedagógicas que trazem um currículo desconectado da prática social o que foi constatado com a pesquisa.

Por outro lado, o professor da escola multisseriada desempenhará tanto melhor o seu trabalho quando se desvencilharem do modelo de organização escolar seriado, adotarem uma visão mais crítica em relação aos conteúdos escolares e lutar para garantir o desenvolvimento dos indivíduos de forma abrangente, o que, no atual desenvolvimento societário, se traduz na necessária apropriação de conhecimentos universais, historicamente sistematizados e referendados pela prática social da humanidade, de forma que os filhos dos trabalhadores do campo se tornem participativos e transformadores da estrutura da sociedade atual.

\section{REFERÊNCIAS}

ARROYO, M. G. Escola: terra de direito. Prefácio. In: ROCHA, M. I. A.; HAGE, S. M. (Org.). Escola de direito: reinventando a escola multisseriada. Belo Horizonte: Autêntica, 2010 .

BEZERRA NETO, L. Educação do campo ou educação no campo? Revista HISTEDBR, on-line, Campinas, n. 38, p. 150-168, jun. 2010. Disponível em: <http://www.histedbr. fe.unicamp.br/revista/edicoes/38/art12_38.pdf>. Acesso em: 20 nov. 2017. 


\section{Revista HIISTEYIDIR On-line}

ISSN: $1676-2584$

Artigo

doi: $10.20396 /$ rho.v18i1.8645922

BRASIL. Censo Escolar da Educação Básica de 2016: Notas Estatísticas. Brasília: DF, fev. 2017. Disponível em: <http://download.inep.gov.br/educacao_basica/censo_escolar/notas estatisticas/2017/notas_estatisticas_censo_escolar_da_educacao_basica_2016.pdf.>. Acesso em: 05 dez. 2017.

BRASIL. INEP/MEC. Panorama da educação do campo. Brasília, 2007. Disponível em: $<$ http://portal.mec.gov.br/secad/arquivos/pdf/educacaodocampo/panorama.pdf >. Acesso em: 12 ago. 2015.

BRASIL. Lei ${ }^{\circ}$ 12.960, de 27 de março de 2014. Estabelece sobre as diretrizes e bases da educação nacional, para fazer constar a exigência de manifestação de órgão normativo do sistema de ensino para o fechamento de escolas do campo, indígenas e quilombolas. Disponível em: <http://www.planalto.gov.br/ccivil_03/_Ato20112014/2014/Lei/ L12960.htm>. Acesso em: 05 mar. 2016.

CARDOSO, M. A. A organização do trabalho didático nas escolas isoladas paulistas: 1893 a 1932. Tese (Doutorado em Educação) - Universidade Estadual de Campinas. Campinas, SP, 2013.

DUARTE, N. A pedagogia histórico-crítica no âmbito da história da educação brasileira. In: PINHEIRO, A. C. F.; CURY, C. E.; ANANIAS, M. (Org.). História da educaçãa brasileira: experiências e peculiaridades. João Pessoa: Ed. da UFPB, 2014. p. 29-50. Disponível em: <http://boletimef.org/biblioteca/3087/A-pedagogia-historico-critica-nahistoria-da-educacao>. Acesso em: 20 dez. 2017.

FURTADO, E. D. P. Estudo sobre a educação para a população rural no Brasil.

PROYECTO FAO; UNESCO; DGCS ITALIA; CIDE; REDUC, 2004. Disponível em: <red-ler.org/estudio_educacion_poblacion_rural_brasil.pdf>. Acesso em: 26 jan. 2018.

GAMA, C. N.; DUARTE, N. Concepção de currículo em Dermeval Saviani e suas relações com a categoria marxista de liberdade. Interface, Botucatu, v. 21, n. 62, jul./set. 2017. Disponível em: <http://www.scielo.br/scielo.php?script=sci_arttext\&pid=S141432832017000300521>. Acesso em: 17 nov. 2017.

HAGE, S. A. M. Transgressão do paradigma da (multi)seriação como referência para a construção da escola pública do campo. Educ. Soc., Campinas, v. 35, p. 1165-1182, out./dez., 2014.

MARSIGLIA, A. C.; SAVIANI, D. Prática pedagógica alfabetizadora à luz da psicologia histórico cultural e da pedagogia histórico-crítica. Psicologia em Estudo, Maringá, v. 22, n. 1, p. 3-13, jan./mar. 2017.

MARTINS, L. M.; MARSIGLIA, A. C. G. Contribuições para a sistematização da prática pedagógica na educação infantil. Cadernos de Formação RBCE, p. 15-26, mar. 2015. Disponível em: <revista.cbce.org.br/index.php/cadernos/article/download/2079/1035>. Acessado em: 04 jan. 2018. 
MARTINS, L. M. Os fundamentos psicológicos da pedagogia histórico-crítica e os fundamentos pedagógicos da psicologia histórico-cultural. Revista Germinal: Marxismo e Educação em Debate, Salvador, v. 5, n. 2, p. 130-143, dez. 2013.

MEDEIROS, M. D. de. A escola rural e o desafio da docência em salas multisseriadas: o caso do Serindró norte riograndense. Dissertação (Mestrado em Educação) universidade Federal do Rio Grande do Norte, 2010. Disponível em: <https://repositorio.ufrn.br/jspui/bitstream/123456789/14437/1/MariaDM_DISSERT.pdf.> . Acesso em: 08 mar. 2018.

MINAYO, M. C. de. S. O desafio do conhecimento: pesquisa qualitativa em saúde. 2. ed. São Paul; Rio de Janeiro: HUCITEC-ABRASCO, 1993.

ORSO, P. J. Pedagogia histórico-crítica no campo. In: BASSO, J. D.; SANTOS NETO, J. L.; BEZERRA, M. C. dos. S. (Org.). Pedagogia histórico-crítica e educação no campo: história, desafios e perspectivas atuais. São Carlos: Pedro \& João; Navegando, 2016.

PARO, V. H. Administração escolar e qualidade de ensino: o que os pais ou responsáveis têm a ver com isso? In: BASTOS, J. B. (Org.). Gestão democrática. 2. ed. Rio de Janeiro: DP \& A, 2001.

SAVIANI, D. A pedagogia histórico-crítica na educação do campo. In: BASSO, J. D.; SANTOS NETO, J. L.; BEZERRA, M. C. dos. S. (Org.). Pedagogia histórico-crítica e educação no campo: história, desafios e perspectivas atuais. São Carlos: Pedro \& João; Navegando, 2016.

SAVIANI, D. As concepções pedagógicas na história da educação brasileira. Campinas, UNICAMP, Projeto "20 anos do HISTEDBR", 2005. Disponível em: $<$ http://www.histedbr.fe.unicamp.br/navegando/artigos_frames/artigo_036.html>. Acesso em: 17 ago. 2015.

SAVIANI, D. Escola e democracia: para além da "teoria da curvatura da vara". Revista Germinal: Marxismo e Educação em Debate, Salvador, v. 5, n. 2, p. 227-239, dez. 2013.

SAVIANI, D. Escola e democracia: teorias da educação, curvatura da vara, onze teses sobre a educação política. 39. ed. Campinas, SP: Autores Associados, 2007.

SAVIANI, D. Pedagogia histórico-crítica: primeiras aproximações. Campinas: Autores Associados, 2008.

VÁZQUEZ, A. S. Filosofia da práxis. São Paulo: Expressão Popular, 2011. 


\section{Revista HIISTESIDBR On-lime}

\section{Notas}

${ }^{1}$ Doutoranda em Educação pela Universidade Federal de São Carlos - UFScar. Docente da Universidade Federal do Tocantins. E-mail: klivia@uft.edu.br

2 Doutora em Educação pela Universidade Estadual de Campinas-UNICAMP. Docente da Universidade Federal de São Carlos-UFSCar. E-mail: mc.bezerra12@gmail.com

${ }^{3} \mathrm{O}$ termo etapa de ensino aqui empregado se refere aos níveis de ensino, que nas escolas da zona rural, além de serem multisseriadas, são também multietapas, por exemplo: estudam juntos, na mesma sala de aula, alunos da educação infantil (pré-escolar) e a $1^{\text {a }}$ fase do ensino fundamental.

${ }^{4}$ Entendemos categorias empíricas tal como Minayo (1993, p. 94) define: “[...] são aquelas construídas com finalidade operacional, visando o trabalho de campo (a fase empírica) ou a partir do trabalho de campo. Elas têm a propriedade de conseguir apreender as determinações e as especificidades que se expressam na realidade empírica”.

5 De acordo com o Portal do Ministério da Educação Pacto Nacional pela Alfabetização na Idade Certa tem por objetivo assegurar a todas as crianças estejam alfabetizadas até oito anos de idade, ou seja, ao final do $3^{\circ}$ ano do ensino fundamental. Disponível em: <http://pacto.mec.gov.br/index.php.>. Acesso em: 17 no. 2017.

${ }^{6}$ A maior parte dos professores de classes multisseriadas ainda divide os alunos em fileiras de carteiras para cada ano escolar de modo que o primeiro ano fica em uma fileira, o segundo em outra e assim sucessivamente de acordo com a quantidade de séries presentes na classe. Dividem da mesma forma o quadro negro, para registrar as tarefas para cada ano.

7 Devido a complexidade e do objetivo proposto neste artigo, nesse momento não abordaremos sobre o Programa Bolsa Família, ficando aberto para ser aprofundado numa próxima pesquisa.

Submetido em: 03/05/2016

Aprovado em: 15/11/2017

Publicado em: 11/04/2018 